\title{
The Linguistic Atlas of the East of Guilan on the Basis of Morphological Analysis (Lexical - Inflectional)
}

\author{
Maryam Mahlouji Afshar \\ M.A in General linguistics, Islamic Azad University, Central Tehran Branch \\ Iran Kalbassi \\ PH.D, Professor of Islamic Azad University, Central Tehran Branch and Institute for Humanities and Cultural \\ Studies
}

\begin{abstract}
This article, in line with "The National Project of the Dialectology", aims to provide a linguistic atlas in the East of Guilan province. Due to the large number of speakers in the southern edge of the Caspian Sea and many differences between dialects and accents, this area has great importance linguistically and providing the linguistic atlas in representation and introduction of dialects in this land can be an important achievement to access the indigenous, cultural, social and historical studies among linguistics and persons who are interested in culture. In order to achieve this principal issue, there has been investigated the morphological differences and similarities (lexical - inflectional) of language varieties in the East of Guilan province with the standard Persian- even more than phonetic and syntactic analysis- and they can have the principal role in providing the linguistic atlas. So in this article, through presenting the morphological evidences (lexical inflectional) and comparing them with standard Persian, there has been marked a dialect with different accents- the Guilaki dialect from the East of Guilan province and it has been depicted for linguistic atlas. The study was conducted by library and field method and by collecting data from a questionnaire consisting of 100 words and sampling from 20 villages in the East of Guilan province- from Astaneh Ashrafieh to the end of the eastern border of Guilan province (Chaboksar). The data obtained by each village has been considered in the tables related to each word and has been moved on the map of region after comparing with the standard Persian and finally the linguistic atlas has been made. To achieve genuine accents, the speakers of middle-aged who spent much of their life in the area have been helped and villages have been considered with more phonetic differences in accent.
\end{abstract}

Keywords: language, dialect, accent, linguistic atlas, language variety, standard language

\section{INTRODUCTION}

Language has been known as a systematic phenomenon used for communication among people in all human societiessmall and remote communities. The importance of the recognition of this phenomenon and the scientific study of this phenomenon has been led to the emergence of new knowledge as "linguistics" in the field of humanities. Linguistics is the scientific study of language and one of its branches is to collect and investigate various dialects and accents scientifically called "dialectology". Variety of different dialects and accents in any language highlights the importance of this science. Also, collecting the dialects of each country and geographical region not only is important in preserving oral heritage of every people and nation and makes possible historical-comparative study of languages but also can provide studies related to linguistics such as anthropology, sociology, etc. The implementation of the information obtained from these language varieties on the map provide the dialect or linguistic atlas leading to become easier the study of dialects.

\section{Expressing Issue}

The presence of Guilak nation and the dialects in Guilan province- whether in the East or in the West of Guilan- because of numbers of speakers and the various differences in their dialects and accents in a similar geographical situation, lead to that this area to be very important due to linguistic study. Providing the linguistic atlas can be an important step to represent and introduce the diverse dialects and can facilitate cultural, indigenous, historical and social studies and help the linguists and who are interested in the culture to have the access to a comprehensive study of a dialect with different accents that are different due to phonetic, morphological, lexical and syntactic issues. In this study, the morphological evidences (lexical - inflectional) can be useful even more than phonetic and syntactic evidences in providing linguistic atlas.

\section{Purpose and Importance of Study}

Providing the linguistic atlas, for any country and any language, has been considered an important and positive step in order to gather different dialects in the form of the encyclopedia that can be used in finding common points of different dialects and the structure of the standard and common language of that country and the enrichment of the national language of a nation and even the promotion of language learning. Providing the linguistic atlas of the East of Guilan province is a scientific research in this field in order to fulfill the efforts of our great masters in linguistics - Dr. Yadollah Samareh and Dr. Iran Kalbassi - and the other researchers who have taken steps in realization of "The National Project of the Dialectology of Iran" that the results of this project can be used by the researchers of other courses and even nonPersian language researchers.

\section{Questions of the Study}


There are some questions related to this study as follows:

1 - Are the language varieties of the East of Guilan province different, morphologically, with the standard Persian?

2 - Are the language varieties of the East of Guilan province different, lexically, with the standard Persian?

3 - Is there Guilaki dialect with different accents in the East of Guilan province?

\section{Studies of Iranian Researchers}

Iranian researchers who have studies on Guilaki dialect are as follows:

- Sotoudeh has published the book entitled "Guilaki Dictionary” in 1953.

- Payandeh Langaroudi has published the book entitled "A Dictionary of Guilaki and Deilami Proverbs and Idioms" in 1968, the book "A Dictionary of Guilaki and Deilami" in 1987 and the book "The Religions and Believes of Guilaki and Deilami” in 1998.

- $\quad$ Sartippour has published the book entitled "Grammatical Characteristics and A Dictionary of Guilaki Terms" in 1990.

- Kalbassi has published two works entitled "The Dialect of Kalardasht (Roudbarak)" and "A Descriptive Dictionary of Linguistic Varieties in Iran" in 1997 and 2009.

- $\quad$ Bakhshzad Mahmoodi has published the book entitled "Guilaki Grammar" in 2011.

Also, there have been implemented various theses in this field as follows:

- Shokouhi, 1999, "The Verb Phrase Structure in the Dialect of Guilaki in Langaroud".

- Abdollahzadeh, 2003, "The Phonetic and Dialect System in Astaneh Ashrafieh".

- $\quad$ Azari Hamidian, 2003, "The National Project of the Dialectology of Iran, No. 2 (40 Villages in Mazandaran and Guilan)".

- $\quad$ Abdollahtabar Ghasemabadi, 2011, "The National Project of the Dialectology of Iran, No. 7 (30 Villages in the East of Guilan)".

And some articles related to this study as follows:

- Basirat and Famian, 2011, "Towards Mapping out A Guilaki Dialect Atlas".

- Mir Hashemi Jorshari, 2012, "The Verbal Prefix /bv-/ in the Simple Past Tense of Guilaki from Creation to Declension".

- Shabani, 2014, "The Description and Analysis of the Discontinuous Focus in Guilaki Language (Eshkevarat Dialect)".

\section{Studies of Non-Iranian Researchers}

- Gmelin, biological and ethnological scientist that we owe him the first awareness of Guilaki dialect. He published the book "Reise Durch Russland Zur Untersuchung Der Drey Naturreiche" in Saint Petersburg in 1775.

- Chodzko, Polish researcher, published the book "Specimens of Popular Poetry of Persia" in London in 1842.

- Christensen, the professor of Persian Philology in the University of Copenhagen, wrote the book "Dialecte Guiläkî De Recht". It was translated by Khomamizadeh in 1995.

- Schmit, the contemporary professor, presented a book entitled "Compendium Linguarum Iranicarum". It has been translated into Persian by Baghbidi in 2003.

\section{Methodology}

There has been used the library and field method in this regard. In the library method, there has been studied the books, articles and other theses related to this project as well as another dialect researches that has been done in this geographic area. In the field method, the data has been gathered by sampling and collecting linguistic data through interviews with the native speakers of the region.

\section{Statistical Population}

In this study, there have been selected 20 villages in the East of Guilan province with the highest linguistic differences. In this plan, the native speakers of the villages participated in the interview who lived there for many years with the age average 20-55 years. Because people less than twenty years, due to their influence of mass media, and people over 55 years, due to the deformation of the organs of speech, reduce the possibility of collecting data correctly. In each village there has been interviewed at least three native speakers that the most of them were educated in order to convey the

1164 | P a g e 
concepts and collect the data more accurately. Also most speakers were male. The selection was done randomly among the different categories.

\section{Data Collection Method}

The method of data collection was the field method through interviews with the speakers on a field based on a questionnaire consisting of 100 words. Thus, during the interview, the speaker was asked to express each of the 100 words in the questionnaire based on his language intuition in order that the researcher can record them by using the tape recorder. In cases that it was necessary to transfer the concept of such words accurately, there has been used them in the sentences.

\section{Data Analysis Method}

In the method of data analysis that has been the descriptive-analytic method, after recording and collecting data, there has been performed their phonetic transcriptions in the tables provided for each word based on the name of the village and its geographical situation. After comparing the words with the standard Persian, the result was marked with signs on the map of the area. And finally the linguistic atlas of the East of Guilan province- from Astaneh Ashrafieh to the end of the eastern region of Guilan province (Chaboksar) has been prepared showing the dispersion of accent, dialect and language in the region.

\section{Studied Grammatical Points}

\section{The plural sign}

Sometimes, the plural sign [on] in Guilaki is placed against [hâ] in the standard Persian:

draxton

\section{"Trees"}

draxthâ

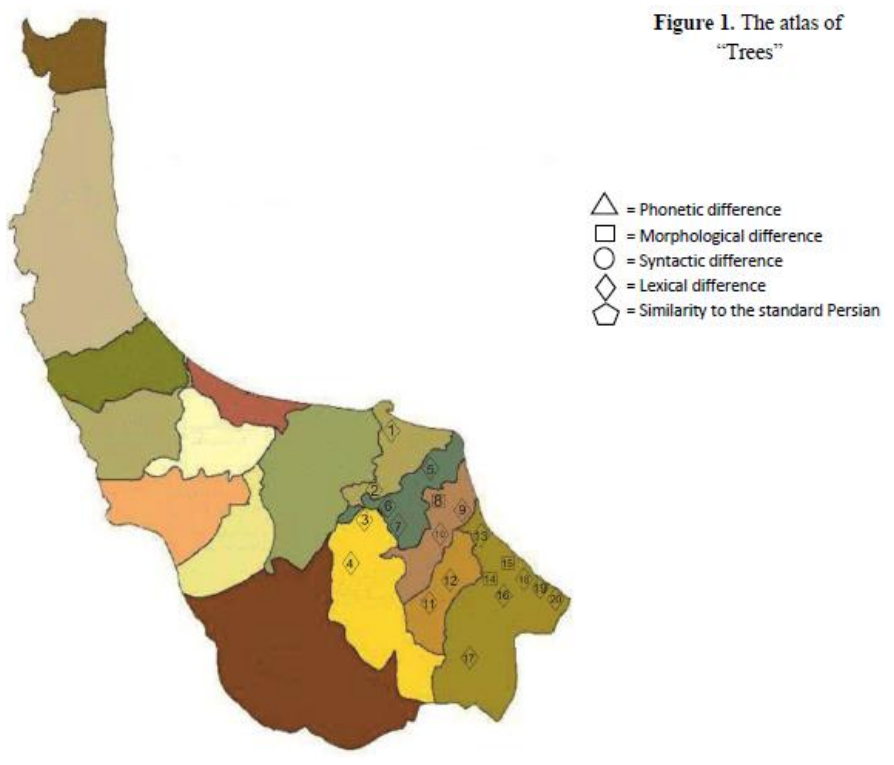




\section{The Deletion of Genitive Sign}

Sometimes adjective and noun are reversed in Guilaki and the genitive sign is: - $\varnothing$

xujir vača:n

"Good boys"

pesarâne xub

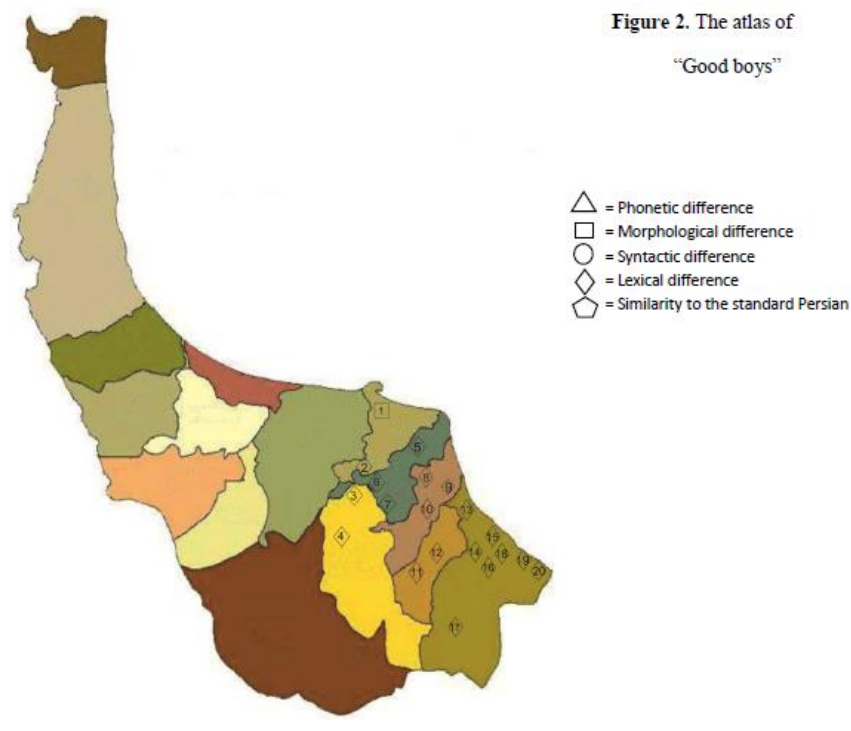

The progressive sign with the intransitive verb

The progressive sign of the intransitive verb in Guilaki is: - $\varnothing$ nišinim / nišənim / nišanim / nišim "We sit down"

$\underline{\text { minešinim }}$

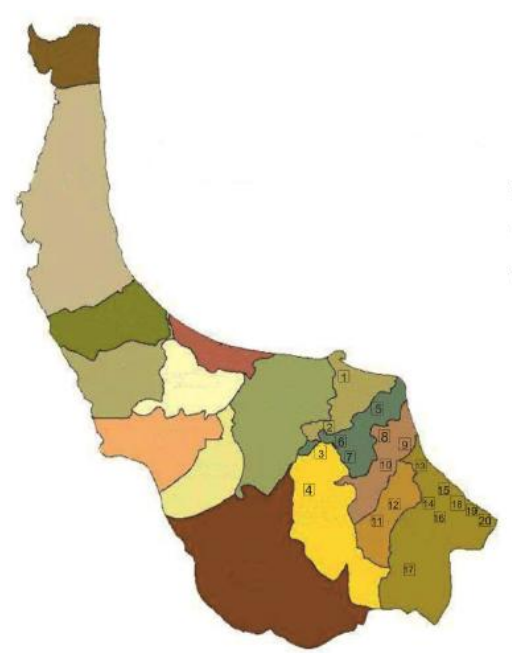


The progressive sign with the transitive verb

The progressive sign of the transitive verb in Guilaki is: - $\varnothing$

xorim

"We eat"

$\underline{\text { mixorim }}$

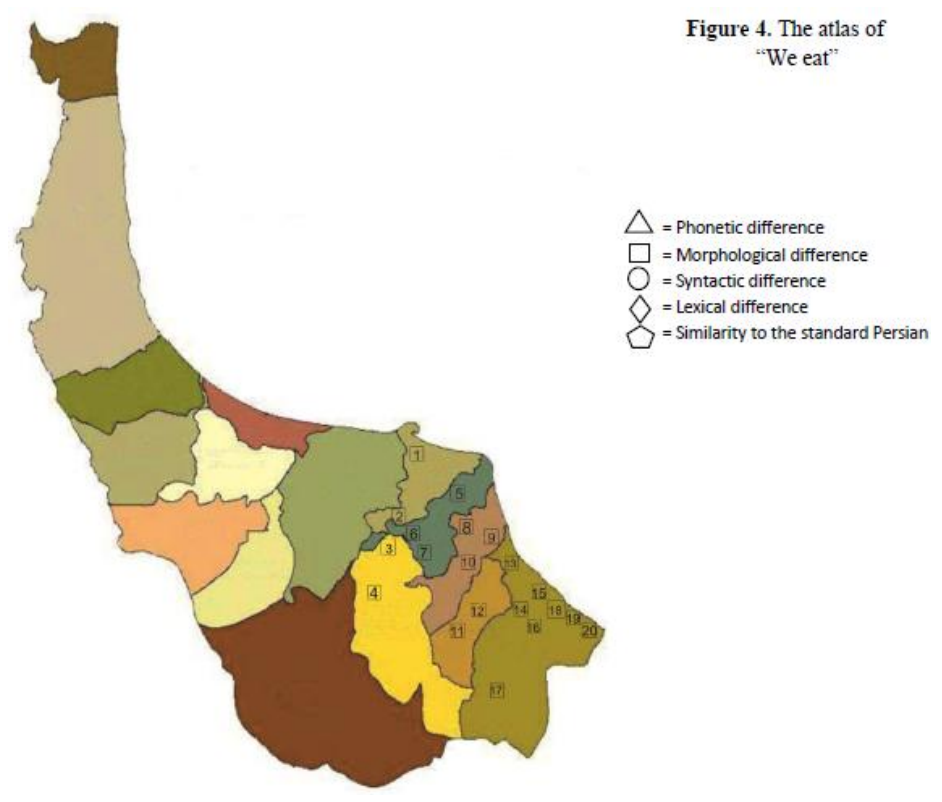

The independent subject pronouns

$\mathrm{mu} / \mathrm{mo}$

man 


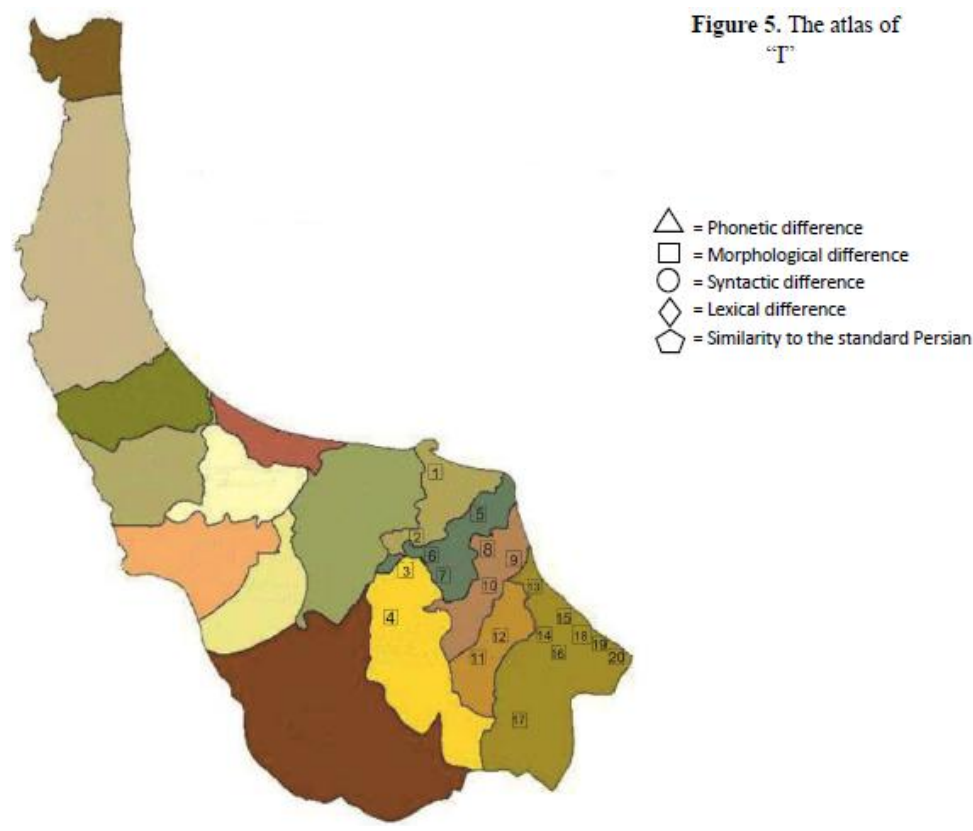

The dependent subject pronouns with the intransitive verb

nišənəm / nišinm̧

minešinam

"I sit down"

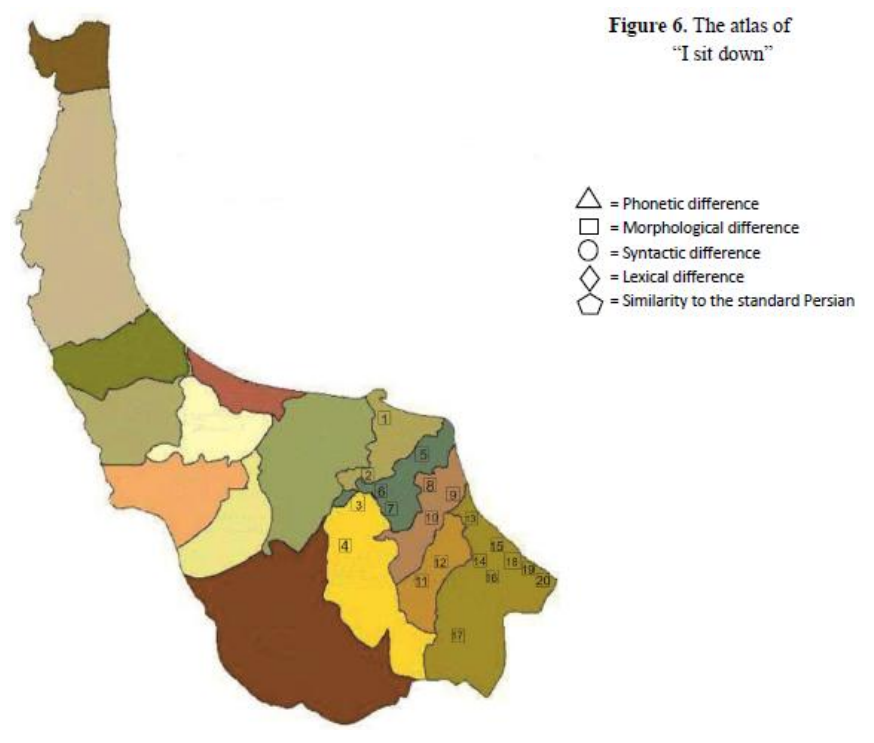

The dependent subject pronouns with the transitive verb

xonəm / xorama / xormə

mixoram

$$
\text { "I eat" }
$$




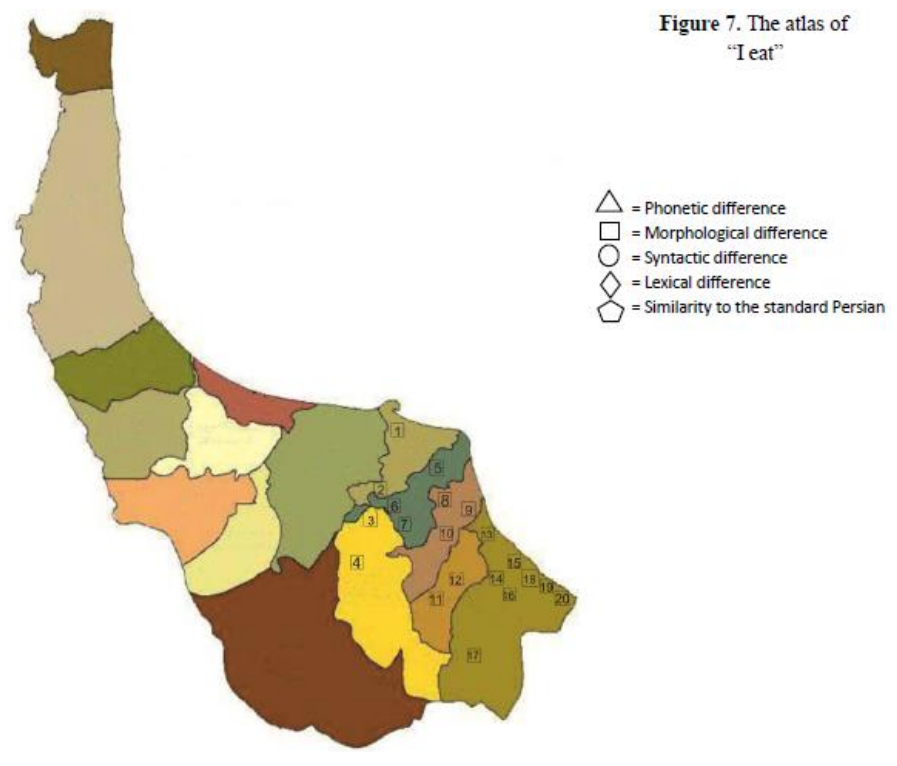

The verbal prefix in the simple past tense with the transitive verb boxordim / buxordim

"We ate"

xordim

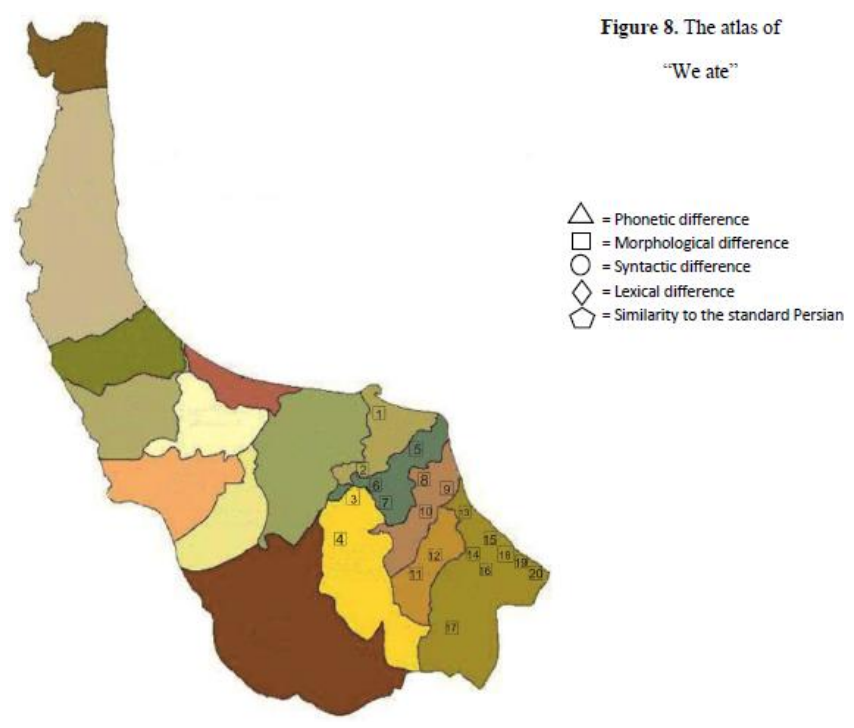

The verbal prefix in the simple past tense with the intransitive verb 
baništim / beništim / bəništim

nešastim

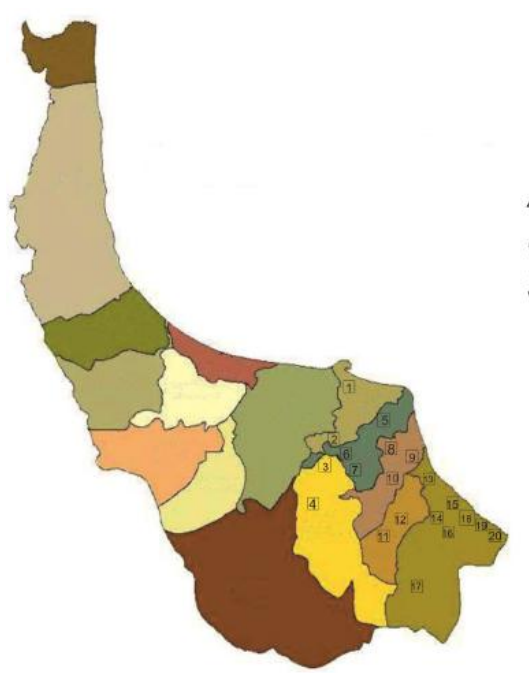

\section{Lexical differences}

kuta:y / rikə

$\triangle$ = Phonetic difference

= Morphological difference

$8=$ Lexical difference
Figure 9 . The atlas of

"We sat down"

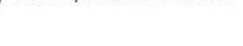

\section{"We sat down"}

\section{"Boy"}

pesar

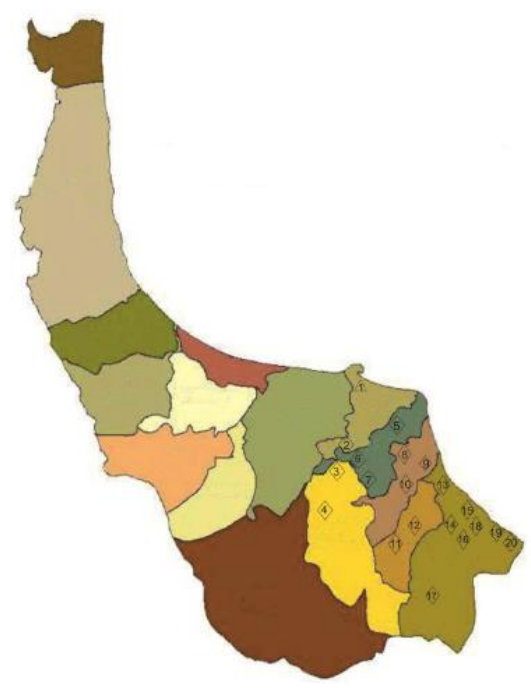

Figure 10. The atlas of

"Boy"

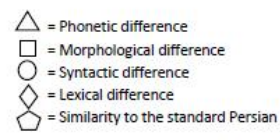

lâku / kiǰâ

doxtar 


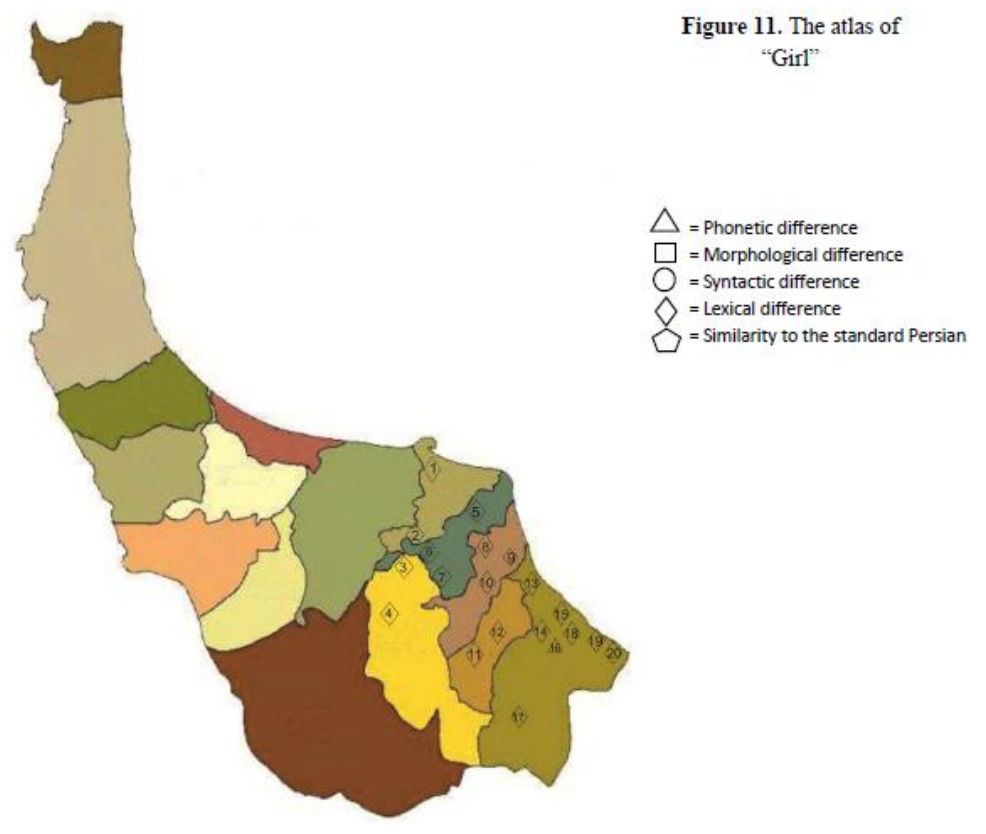

\section{Conclusion}

By analyzing differences and similarities of research data with the standard Persian shown on the maps, we can realize the morphological differences, whether lexical or inflectional, in most villages of mentioned region compared to the standard Persian. Therefore, due to the current study, we can draw the linguistic atlas of the East of Guilan province and based on the concept of the language, dialect and accent, approve a kind of dialect as Guilaki dialect with different accents in this region.

Figure 12. The final linguistic atlas of the studied region

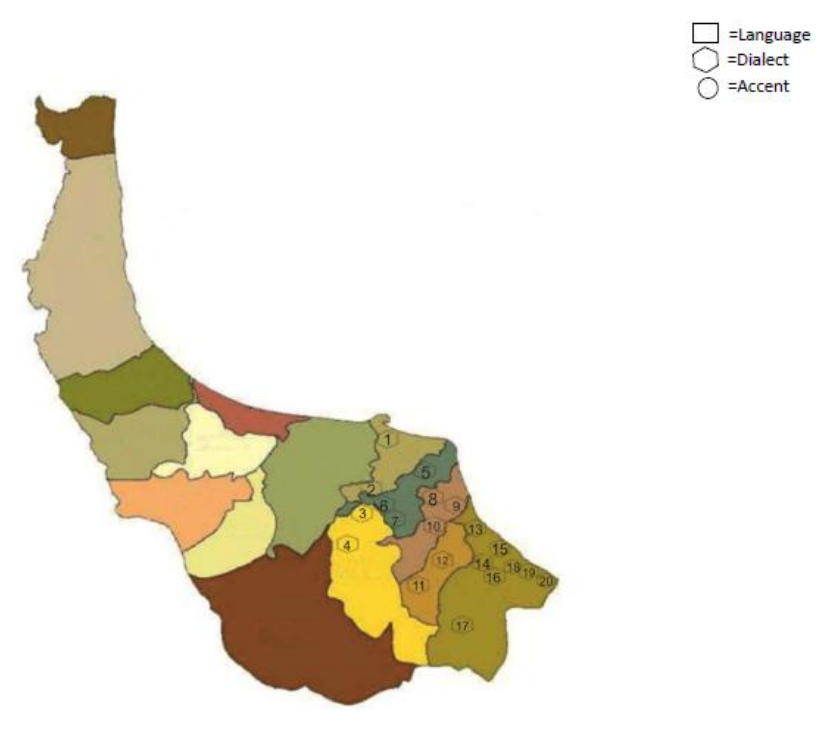

\section{REFERENCES}

- Abdollahtabar Ghasemabadi, Mahdieh, 2011, "The National Project of the Dialectology of Iran, No. 7 (30 Villages in the East of Guilan)", Master Thesis, Islamic Azad University Central Tehran Branch

- Abdollahzadeh, Arsalan, 2003, "The Phonetic and Dialect System in Astaneh Ashrafieh", Master Thesis, Islamic Azad University Central Tehran Branch 
-Azari Hamidian, Shadi, 2003, "The National Project of the Dialectology of Iran, No. 2 (40 Villages in Mazandaran and Guilan)", Master Thesis, Islamic Azad University Central Tehran Branch

- Bakhshzad Mahmoodi, Jafar, 2011, "Guilaki Grammar", Rasht: Guilakan Publication

- Basirat, Vahid and Ali Reza Gholi Famian, 2011, "Towards Mapping out A Guilaki Dialect Atlas", Quarterly Adab Pazhuhi, No. 17, Fall 2011, pp. 165-183

- Chodzko, Alexandre, 1842, "Specimens of Popular Poetry of Persia", London

- Christensen, Arthur, 1995, "Dialecte Guiläkî De Recht", translated by Khomamizadeh, Tehran: Soroush

- Gmelin, S.G., 1775, "Reise Durch Russland Zur Untersuchung Der Drey Naturreiche", Saint Petersburg

- Kalbassi, Iran, 1997, "The Dialect of Kalardasht (Roudbarak)", Tehran: Institute for Humanities and Cultural Studies

- Kalbassi, Iran, 2009, "A Descriptive Dictionary of Linguistic Varieties in Iran", Tehran: Institute for Humanities and Cultural Studies

- Mir Hashemi Jorshari, Seyyed Hannan, 2012, "The Verbal Prefix /bv-/ in the Simple Past Tense of Guilaki from Creation to Declension", Quarterly Adab Pazhuhi, No. 20, Summer 2012, pp. 111-134

- Payandeh Langaroudi, Mahmoud, 1968, "A Dictionary of Guilaki and Deilami Proverbs and Idioms", Tehran: Iranian Cultural Foundation

- Payandeh Langaroudi, Mahmoud, 1987, "A Dictionary of Guilaki and Deilami", Tehran: Amir Kabir

- Payandeh Langaroudi,Mahmoud, 1998, "The Religions and Believes of Guilaki and Deilami", Tehran: Institute for Humanities and Cultural Studies

- Sartippour, Jahangir, 1990, "Grammatical Characteristics and A Dictionary of Guilaki Terms", Rasht: Guilakan Publication

- Schmit, Rüdiger, 2003, "Compendium Linguarum Iranicarum", translated by Hassan Rezaee Baghbidi and others,

Tehran: Ghoghnoos

- Shabani, Mansour, 2014, "The Description and Analysis of the Discontinuous Focus in Guilaki Language (Eshkevarat

Dialect)", Quarterly Adab Pazhuhi, No. 30, Winter 2014, pp. 81-99

- Shokouhi, Ali, 1999, "The Verb Phrase Structure in the Dialect of Guilaki in Langaroud",Master Thesis, Tarbiat Modarres University

- Sotoudeh, Manouchehr, 1953, "Guilaki Dictionary", Tehran: Iranian Association

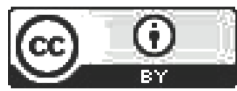

This work is licensed under a Creative Commons Attribution 4.0 International License.

DOI : 10.24297/jal.v7i1.4620 